\section{DERLEME MAKALE}

\section{Aylin Yaman ${ }^{1}$ \\ Hakan Yaman ${ }^{2}$}

${ }^{1}$ Antalya Eğitim ve Araştırma Hastanesi, Nöroloji Bölümü, Antalya

${ }^{2}$ Akdeniz Üniversitesi Tıp Fakültesi Aile Hekimliği AD, Antalya

\section{Yazısma Adresi}

Prof. Dr. Hakan Yaman

Akdeniz Üniversitesi Tip Fakültesi

Aile Hekimliği AD, 07059-Antalya

Tel: 00902422496860

Faks: 00902422496861

E-mail:hakanyaman@akdeniz.edu.tr

Geliş Tarihi: 04.04.2014

Kabul Tarihi: 15.08.2014

Konuralp Tip Dergisi

e-ISSN1309-3878

konuralptipdergi@duzce.edu.tr

konuralpgeneltip@gmail.com

www.konuralptipdergi.duzce.edu.tr

\section{Aile Hekimliğine Başvuran Yaşlı Bireylerde Bilişsel Değerlendirme}

ÖZ

Aile sağlığı merkezleri muhtelif sağlık sorunları ile başvuran yaşlı bireylere hizmet sunmaktadırlar. Aile hekimleri gerek gündelik poliklinik çalışmaları sırasında, gerekse ev ziyaretleri sırasında bilișsel sorunları olan hastalar ile karşılaşmaktadırlar. $\mathrm{Bu}$ hastalar ile iletişim kurmak ve sağlık sorunlarını uygun şekilde yönetmek amacıyla hastaların birlikte olduğu kişilerin görüşlerine başvurulur. Bilişsel sorunlara en sık demans ve deliryum neden olmaktadır. Demansın taramasında tek ya da birden fazla bilişsel alanı değerlendiren tarama testleri kullanılabilir. Zaman yeterli olursa Mini Mental Durum Muayenesi yapılması uygundur. Olanaklıysa aile hekimlerince uygun geriyatrik değerlendirme de yapılmalıdır. Bunun için Aile Sağlığı Merkezlerinde ve ev ziyaretlerinde Yaşlı Dostu Aile Sağlığı Merkezi Enstrümanı kullanılıp, muayene edilen yaşlı hastalarda deliryum ve demans tabloları dışlanmalıdır. Tarama testleri müspet sonuçlanır ise ileri testler ile yine enstrüman seti çerçevesinde tanı doğrulanmalıdır.

Anahtar Kelimeler: Aile Hekimliği, Birincil Sağlık Bakımı, Yaşlanma, Bilişsel Bozukluk, Demans, Deliryum

\section{The Cognitive Evaluation of Elderly Individuals in Family Practice}

\begin{abstract}
Family Health Centers serve elderly people with a variety of health problems. Family physicians frequently encounter patients with cognitive problems during home visits or outpatient examinations. The view of accompanying person is sought to establish communication and to manage health problems appropriately. Dementia and delirium are common reasons for cognitive problems. During screening of dementia one or more cognitive domains are examined. The Mini Mental State Examination scale should be utilized and family physicians should establish a geriatric assessment if time is available. The Elderly Friendly Family Health Center Instrument is an appropriate tool for home visits and outpatient office and delirium or dementia should be ruled out after examination. Further evaluation needed to be initiated after scoring positive for dementia and delirium. The second part of the Elderly Friendly Family Health Center Instrument should be recommended for this step.
\end{abstract}

Keywords: Family Practice, Primary Health Care, Aging, Cognition Disorders, Dementia, Delirium 


\section{GíRiş}

Yaşlı bireyler aile sağlığı merkezlerine sıklıkla sağlık sorunları ile başvurmaktadırlar. Sorunları epiziodik bir süreci kapsayabileceği gibi, kronik de olabilmektedir. Epizodik sağlık sorunları basit gibi görünse de yakınma ve bulgularının atipik sunumu, laboratuvar bulgularının değişken olması, komorbiditenin varlığı gibi faktörler durumu karmaşıklaştırabilir. Kronik sağlık sorunlarında ise polifarmasinin varlığı, ilaç uyumunun zayıfllğ̆ , yaşam tarzına yönelik değişim gayretlerinin azlığı, iletişim sorunlarının varlı̆̆ (afazi, işitme sorunları) sağlık hizmetlerini aksatmakta, zorlaştırmakta ve durumun karmaşık bir hal almasına neden olmaktadır (1-3). Sıklıkla acillerde yaşanmakla birlikte, aile sağlığ merkezlerinde ve ev ziyaretleri sırasında yaşlı hastanın değişken bir mental duruma sahip olduğu (deliryum ve demans) gözlenmektedir (4). Bu durum hem hasta ile kurulacak olan iletişime engel olmakta, hem de hastanın özerkliği konusunda bazı soru işaretleri ortaya koymaktadır. Hastanın bilişsel durumu ile ilgili değerlendirme yapılırken, bakım veren kişinin görüşüne başvurulmaktadır $(5,6)$.

Bilişsel durumunun etkilendiği iki temel klinik tablo ile karşılaşırız: deliryum ve demans. Deliryum (akut konfüzyonel durum) akut veya subakut gelişen, bilişsel işlevlerde dalgalanma ile seyreden, bozulmuş dikkat ve bilinç düzeyi ile giden bir sorundur ve acile sık başvuru nedenleri arasında bulunur. Olguların ancak \%35'i fark edilebilir ve siklıkla altta yatan bir nedenden dolayı gözden kaçar (sıklıkla demans, inme ya da TİA gibi nörolojik sorunların varlığında) (4,7). Deliryum saatler veya günler içerisinde gelişir. Deliryum klinik olarak tam belirgin hale gelmeden önce, hastaların prodrom huzursuzluğu, bozulmuş dikkat ve uyku bozuklukları vardır. $\mathrm{Bu}$ kriter özellikle deliryum ile demansı ayırt eder. Bu kriterin özellikle aile yakınlarına ya da bakım evinde ise bakım veren kişilere ayrıntıyla sorulması gerekmektedir $(4,7,8)$. Acil servis ya da ASM'de bu dalgalanmanın seyrini izlemek mümkün olamayabilir. Deliryumun tanısında DSM-V kriterleri esas alınabilir. Bu kriterlere göre deliryumun beş temel özelliği bulunur. Bunlar dikkat, deliryumun kısa sürede gelişiyor olması (saatler-günler içinde gelişir, dalgalanmalar gösterir), ek olarak bilişte değişiklikler göstermesi (bellek defisiti; yönelimde, dilde, görsel mekânsal işlevler ve algıda bozukluk), bozukluğun başka bir nedenle (nörobilişsel bozukluk) açıklanamaması (demans, koma vb.) ve bozukluğun tıbbi, madde intoksikasyonu ya da kesilmesi ya da ilaç yan etkisine bağlı olmasidır (9).

Dört farklı deliryum tipi bulunur: Genel Tıbbi Duruma Bağlı Deliryum, Madde Kullanımına Bağlı Deliryum, Çoğul Etiyolojiye Bağlı Deliryum ve Başka Yerde Belirtilmeyen Deliryum. Bilişte öncelikle dikkat işlevi etkilenir. Kısa süreli bellek etkilenimi yüksek derecede duyarlıdır (deliryum için $\% 100$ duyarlı ve $\% 33$ seçicidir). Bellek bozukluğu üç madde hatırlama testi ile slnanabilir (Şekil 1). Zaman ve yer yönelimi kaybı gelişebilir (deliryum için \%89 duyarlı ve $\% 63$ seçicidir). Algısal bozukluklar ise sanrı, yanılsama ya da belirgin varsanılardır. Bunlar, görsel, işitsel, taktil, tat alma, koku almaya ilişkin halüsinasyonlar olabilir. Halüsinasyonlar şeklinde algısal bozukluklar deliryum vakalarını \%23'ünde görülebilir. Deliryumun psikometrik değerlendirilmesinde "Konfüzyon Değerlendirme Yöntemi [The Confusion Assessment Method (CAM)]" kullanılabilmektedir (duyarlılığ $1 \% 96$ ve seçiciliği \%93). Bu ölçeğin Türkçe standardizasyonu ise Akıncı SB ve ark. tarafindan yoğun bakım hastalarında yapılmıştır (duyarlılığı \%65-69 ve seçiciliği \%97). CAM, bellek bozukluğu ve yönelim bozukluğunu değerlendiremez (10). Demansa ilişkin değerlendirmede ise mental durum değerlendirilmelidir. Mini Mental Durum Değerlendirmesi 1975 yllından beri kullanılmaktadır. Ülkemizde Türkçe standardizasyonu bulunmaktadır (11).

Tablo 1. Akut Konfüzyonel Durum ile Bilişsel Bozukluk Farkı

\begin{tabular}{lcc}
\hline & $\begin{array}{c}\text { Akut } \\
\text { Konfüzyonel } \\
\text { Durum }\end{array}$ & $\begin{array}{c}\text { Bilişsel } \\
\text { Bozukluk }\end{array}$ \\
Akut Başlangıçl & +2 & 0 \\
Algı Bozukluğu & +2 & +1 \\
Bellek Bozukluğu & +3 & +3 \\
Bilinçte Dalgalanma & +3 & 0 \\
Dikkat Bozukluğu & +3 & +1 \\
Düsünce Bozukluğu & +3 & +3 \\
Enkoherans & +2 & +1 \\
Gün içi Fluktuasyon & +3 & +2 \\
İçörü Kaybı & +2 & +1 \\
Uyanıklı-Uyuma & +2 & +1 \\
Döngüsü Bozukluğu & & \\
Yargılama & +3 & +3 \\
Bozukluğu & & \\
Yönelim Bozukluğu & +2 & +2 \\
\hline
\end{tabular}

Diğer bir test ise saat çizme testidir (12). Bu test ile uzun süreli bellek, zihinsel yoğunlaşma, soyut düşünme, görsel-mekansal işlevler ve planlama yetileri değerlendirilir. Saati çizebilmek için görme ve çizme yetisinin yerinde olması gerekir. Rahatlıkla uygulanır ve 
değerlendirilmesinin yüksek derecede tutarlı olduğu gösterilmiştir. Mini-Cog birincil bakımda uygulanmak üzere geliştirilmiştir (duyarlılığ $\% 77$ ve seçiciliği \%85). Saat çizme testi ile üç madde hatırlama testlerini içermektedir. Önce üç kelime verilir, sonra saat $11^{\prime}$ i 10 geçe çizdirilir ve sonra da üç kelimeyi hatırlaması istenir. Her doğru yanıta bir puan verilir. Normal değer 3 puan ya da doğru çizilmiş saat ile 1 ya da 2 puan olarak kabul edilir (13). Ancak Türkçe standardizasyonu bulunmamaktadır. Bunun yerine "üç kelime hatırlama" ve "saat çizme testinin" uygulanması faydalı olabilir. Bu iki bilişsel alana ilişkin değerlendirmelerin müspet çıkması daha ileri bir tarama ve uzman görüşü almak için önemli ipuçları verecektir.

Bilişsel durum aile sağlığı merkezleri, acil sağlık merkezleri ve ev ziyaretleri sırasinda stupor ya da komada olmayan tüm yaşlı hastalarda değerlendirilmelidir. Akut yakınmaları olan yaşlı hastalarda deliryum; kronik, ilerleyici yakınmaları olanlarda ise demans tanısı öncelikle düşünülmelidir $(4,10)$ (Tablo 1).

Aile Sağlığ1 Merkezlerinde ve ev ziyaretlerinde ise Yaşlı Dostu ASM Enstrümanı kullanılıp, buna ek olarak saat çizme testi ile yaşlı hastalarda demans tablosu taranmalıdır (Şekil 1). Deliryumu dişlamak için ise kısa dikkat testi kullanılabilir (Örn. 100 'den yedişer yedişer geriye sayma ya da haftanın günlerini geriye sayma). Ayırıcı tanisinda depresyon gözönünde bulundurulmalıdır $(14,15)$. Tarama testleri müspet sonuçlandığı taktirde hastanın eğitim düzeyine uygun ileri testler ile tanı doğrulanmalıdır.

\section{KAYNAKLAR}

1. Yaman H, Yazıcı S, Sandholzer H. Geriyatrik değerlendirme: Aile hekimliğinde yaşlının kanıta dayalı rehberler 1şı̆̆ında periyodik muayenesi. Türk Aile Hek Derg 2009; 13(1): 27-38.

2. Yaman H, Tekin O. Yaşı Bireyin Değerlendirilmesi. Yıldırım Beyazıt Üniversitesi. AHUZEM. Aile Hekimliği Sürekli Mesleki Gelişim Programı. Yaşlı Sağlığı Modülü. 5.1.Sağlıklı Yaşlanma. v1.0. 2013.

3. Kanevetçi Z. Dünya Sağlık Örgütü Yaşlı Dostu Sağlık Ocağı Projesinin Antalya İlinde Pilot Uygulaması. Akdeniz Üniversitesi, Tıp Fakültesi, Yayımlanmamış Aile Hekimliği Uzmanlık Tezi, Antalya, Ocak 2008.

4. Yaman H, Çifçili S. Bilişsel Bozukluklar: Deliryum. Yıldırım Beyazıt Üniversitesi. AHUZEM. Aile Hekimliği Sürekli Mesleki Gelişim Programı Yaşlı Sağlığı Modülü 5.4.Deliryum v1.0. 2013.

5. Salvi F, Morichi V, Grilli A, Giorgi R, De Tommaso G, Dessì-Fulgheri P. The elderly in the emergency department: a critical review of problems and solutions. Intern Emerg Med 2007; 2(4):292-301.

6. Scott T. Altered Mental Status in Older Emergency Department Patient. Emerg Med Clin N Am 2006; 24(2):299-316.

7. Türkcan A. Deliryum. Psikiyatri Dünyası 2001;5(1):15-23.

8. Dönmez MC, Gündoğar D, Demirci S. Deliryum: Nedenleri ve Klinik Yaklaşım. Turkiye Klinikleri J Med Sci 2007; 27:718-24.

9. American Psychiatric Association, Diagnostic and Statistical Manual, 5th ed, Washington: APA Press, 2013.

10. Akıncı SB, Rezaki M, Özdemir H ve ark. Yoğun Bakım Ünitesinde Konfüzyon Değerlendirme Ölçeğinin Geçerlik Güvenilirlik Çalışması. Türk Anest Rean Der Dergisi 2005;33(4):333-41.

11. Güngen C, Ertan T, Eker E, Yaşar R, Engin F. Standardize Mini Mental Test'in Türk Toplumunda Hafif Demans Tanısında Geçerlik ve Güvenilirliği. Türk Psikiyatri Dergisi 2002; 13(4):273-81.

12. Cangöz C, Karakoç E, Selekler K. Saat Çizme Testinin 50 Yaş ve Üzeri Türk Yetişkin ve Yaşlı Örneklem Üzerindeki Norm Belirleme ve Geçerlik-Güvenirlik Çalışmaları. Türk Geriatri Dergisi. 2006;9(3):136-42.

13. Borson S, Scanlan J, Brush M, Vitaliano P, Dokmak A. The Mini-Cog: A Cogntivie (Vital Signs) Measure For Dementia Screening in Multilingual Elderly. Int J Geriatr Psychiatry. 2000; 15(11):1021-7.

14. Villars H, Oustric S, Andrieu S et al. The Primary Care Physician and Alzheimer's Disease: An International Position Paper. The Journal of Nutrition, Health \& Aging 2010; 14(2): 110-120.

15. Age-friendly Primary Health Care Centres Toolkit. Genevre: WHO, 2014. 


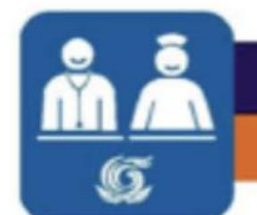

Enstrüman 1: 10 - Dakika Kapsamlı Tarama Testi

\begin{tabular}{|l|l|}
\hline Ne için? & Temel klinik sorunların taranması \\
\hline Kim tarafından? & Sağlık bakım ekibinin tüm üyeleri \\
\hline Ne kadar süre? & 10 dakika \\
\hline
\end{tabular}

(c) Yaşı Dostu Aile Sağlığı

Merkezi Enstrüman Seti,

Dünya Sağlık Örgütü, 2007 10 Dakika Kapsamlı Tarama Testi (adım 1)
Ad-Soyadı:
A. Bellek
1. "3 kelime adını söyleyeceğim: Masa, Bayrak, Elbise. Şimdi sizden bunların adlarını tekrarlamanızı ve bir dakika
sonra bu üç kelimeyi tekrarlamanızı isteyeceğim. Lütfen onları hatırlamaya çalışın"

Tüm 3 kelime söylendi mi? Evet __ Hayır Yanıt eğer hayır ise, "bilişsel değerlendirme"ye gönderiniz.

Bu sorudan sonra Bedensel İşlev Kapasitesine ilişkin sorulara geçiniz (D Maddesi).

B.İdrarını Tutamama

1. "Geçen yıl içerisinde hiç idrarınızı kaçırıp altınızı ıslattınız mı?"
Yanıt eğer evet ise, aşağıdaki Evet__ Hayır
Her iki soruya da yanit evet ise,
"idrar enkontinansı" için ileri değerlendirmeye gönder.

2. "Geçen hafta içerisinde idrar kaçırdınız mı?

2. "Geçen hafta içerisinde idrar kaçırdınız mı?
Evet__ Hayır

C.Depresyon

Yanıt eger evet ise, "depresyon" için ileri

1. "Kendinizi sık sık üzgün veya kederli hissediyor musunuz?" değerlendirmeye gönderiniz.

Evet Hayır

D.Bedensel İşlev Kapasitesi (İmmobilite)

"Aşağıdaki işleri yapabiliyor musunuz?":

"Hızlı yürüme ya da bisiklete binme gibi şiddetli etkinliklerde bulunuyor musunuz?"

"Cam, duvar ya da yerleri slime gibi ağır ev işi yapabiliyor musunuz?"

"Gıda ya da giyim için alıșverișe çıkabiliyor musunuz?"

"Yürüme mesafesi dışında bulunan yerlere gidebiliyor musunuz?"

"Dușta ya da küvette yıkanıp, liflenebiliyor musunuz?"

"Gömlek giyip, düğmelerini ilikleyip, fermuarınızı çekebiliyor musunuz ya da ayakkabılarınızı giyebiliyor

musunuz?"

Sorulan sorulardaki eylemleri yapamıyor veya yardımla ya da başka bir kişinin yardımıyla yapabiliyor ise ve

hayır yanıtını işaretliyor ise "Bedensel Iş̧lev Kapasitesilimmobilite" için ileri değerlendirmeye gönder.

Hasta kendisine daha önce söylenen 3 kelimeyi hatırlayabildi mi?

1. "Üç kelime

1. Geçen 12 ay içerisinede 2 ya da daha fazla kez düştünüz mü?

Evet

Hayır

2. "Yanıtınız hayır ise așağıdaki testi yapınız".

Test: "Sandalyeden ayağa kalk, ona tutunmadan etrafında yürü"

Yapamıor: Evet__ Hayır__ Düzensiz: Evet__ Hayır

Eğer soruda ya da testte yanıtınız evet

İlave sık görülen sorunlar

ise "düşme riski" bakımından ileri değerlendirmeye gönderiniz.

\section{Beslenme}

1. Geçmiş 6 ay içinde beden ağırlığınız ile ilgili bir değişiklik farkettiniz mi?

Arttı __ $\mathrm{kg}$ Düştü ___ $\mathrm{kg}$ (Eğer beden ağırlığı son vizitte kaydedilmiş ise). Eğer sorun saptanırsa

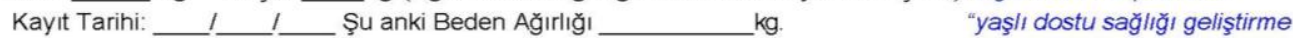

isitme hizmetlerine" ne gönder.

1. Hastanın arkasında durun ve "6","1","9" rakamlarını tekrarlatınız (önce hafif sesle, sonra normal sesle).

Hafif (Fısıltı): Sağ Kulak___ Sol Kulak_ / Normal: Sağ Kulak__Sol Kulak

Hasta her iki kulağıyla da ya da bir kulağıyla duyamıyor (ya da ikisinin herhangi bir kombinasyonu ile

duyamıyorsa) "işitme testi" için hasta yönlendirilir.

Görme

1. "Okurken ya da günlük herhangi bir aktivitenizi yaparken görmekte zorlanıyor musunuz?" (hatta gözlükle bile)

Evet_ Hayır

2 Yanıtnız Evet ise, SNELLEN göz tablosunu tamamlamasını isteyin (önce gözlüksüz ve sonra gözläklü).

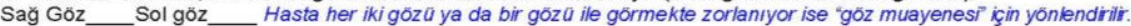

Şekil 1. Yaşlı Dostu Aile Sağlı̆̆ı Merkezi 10 Dakikalık Tarama Testi 